4. Голлербах С.Л. Заметки художника. Лондон: Overseas publ. interchange, 1983. 103 с.

5. Голлербах С.Л. Мой Дом: воспоминания и эссе. Париж: Альбатрос, 1994. 200 с.: ил.

6. Голлербах С.Л. Мысли в стихах. Воронеж: Центр духовного возрождения Черноземного края, 2017. 104 с.

7. Голлербах С.Л. Нью-Йоркский блокнот. Книга воспоминаний. Нью-Йорк, 2013. 252 с.: цв. ил.

8. Голлербах С.Л. Свет прямой и отраженный: Воспоминания, проза, статьи. СПб: Инапресс, 2003. 872 с.: ил.

9. Горячева Ю.Ю. Новая Россия - соотечественники Зарубежья: единое культурное пространство / Ред. Е.М. Кавелина. М.: Этносфера, 2012. 180 с.

10. Еремеева E. «Тройная» жизнь художника. Вернисаж художника Сергея Голлербаха в библиотеке-фонде «Русское зарубежье» // Иные берега. 2008. № 3(11). URL: http://www.inieberega.ru/node/63 (дата обращения: 20.06.2020)

11. Ильинский 0.П. Сергей Голлербах. Мой дом. Воспоминания и эссе. Париж, 1995 Записки русской академической группы в США = Transactions of the Association of Russian-American scholars in the USA. Русская эмиграция не в изгнании, а в послании. 1994. № 27. С. 362-363.

12. Синкевич В.А. К 90-летию Сергея Голлербаха // Связь времен. 2013. Вып. 5. С. 29-32.

\section{Yulia Goryacheva}

Literary scholar, specialist in the writing and culture of Russian emigre society in the 20th and 21st centuries. Author of numerous articles, essays and books on Russian emigre history, literary and culture and on intercultural transfers. Master's degree in Russian, Norwich University (Vermont, USA).

Member of the Moscow Union of Journalists. Member of the Editorial Boards

of the almanacs: «Literary America» and «Link of Times» (USA), tygor67@gmail.com

\section{Memoirs of Serge Hollerbach (USA): Bright portraits} of contemporaries by the outstanding artist of the second wave of emigration

Painter, essayist and writer Serge Hollerbach is the author of unique memoir essays about artistic talent of his time, the Russian emigration's «second wave», primarily DP generation. The monograph is focused on the Russian diaspora of post-WW2 New York and its bright representatives: Mikhail Verbov, Ivan Elagin, Vladimir Odinokov, Leonid Rzhevsky and other famous writers and artists.

Hollerbach's memoir essays also unveil the mystery of his development as an artist and introduces the reader to the author's understanding of art's general principles.

Keywords: Russian emigration, Russia Abroad, Serge Hollerbach, memoir essays, the second emigration wave, artist, poet

\title{
АНТРОПОЛОГИЯ СОВЕТСКОСТИ
}

Изучение феномена советскости и его эволюции предполагает обширную реконструкцию социокультурной среды существования советского человека, в которой в том числе складывались отличительные формы культуры повседневного общения. Коммуникативное поведение советских людей формировалось далеко не только в формате, заданном идеологическим вектором (или в противовес ему). Культурно-языковые коды узнаваемости человека советского рождались в ответ на присутствие в социокультурном пространстве неких коммуникативных «точек входа», каковыми служили в городской среде, например, телефоны-автоматы, автоматы с газированной водой или пивом, стоянки такси и др. Вокруг них спонтанно формировалась особая коммуникативная среда, которая рождала свои «логины и пароли» - словесные и материальные. И не так уж важно, последовательными или параллельными были це почки, которыми они уходили из нашей жизни, - слова, что ты не скажешь... Вместе с ними уходила эпоха, о которой весело, внимательно и с любовью рассказывает автор cmambu.

\section{Владимир Назаров}

\section{Слова, что ты не скажешь...}

Повседневная жизнь советского прошлого рождала культурные коды и поведенческие стереотипы, которые вызывают сегодня не только ностальгические воспоминания людей, рожденных в СССР, но и заслуженный интерес новых поколений, все более увлекающихся антропологией советскости.

Ключевые слова: антропология советскости, социокультурное пространство города коммуникативное поведение, коммуникативная среда, культурный код, реконструкция

\section{Назаров}

Владимир Борисович,

экономист, маркетолог,

член Совета Гильдии маркето-

логов РФ, член Союза журналистов России (Москва), vlad284@mail.ru
В современном цифровом мире старая добрая беседа становится редкостью, доступной истинным ценителями межличностного общения. Разговор онлайн главной своей задачей ставит передачу информации, он полон специфического сленга, мемов, аббревиатур. Зачастую кажется, что семидесяти- и семнадцатилетние говорят на разных 
языках, просто похожих по звучанию. Появилось множество новых слов и выражений, однако не меньшее их количество безвозвратно исчезает из обиходной речи совсем недавнего прошлого. Они уходят от нас вместе с предметами материальной культуры, их породившими, но остаются жить на страницах книг, в кинофильмах, подшивках старых газет. Повседневная жизнь советского прошлого рождала культурные коды и поведенческие стереотипы, которые вызывают сегодня не только ностальгические воспоминания людей, рожденных в СССР, но и заслуженный интерес новых поколений, все более увлекающихся антропологией советскости.

Если сегодня вы обратитесь к прохожим с просьбой разменять деньги по две копейки, от вас отмахнутся или посмотрят, как на шутника. Давно в наших кошельках нет бесполезной мелочи, а двухкопеечные монеты из медно-никелевого сплава остались разве что в коллекциях нумизматов. Кстати, дорожают они год от года. Главное назначение этих кругляков на огромном постсоветском пространстве почти забыто. Между тем каких-то 30-40 лет назад никто не выходил из дома, не имея в кармане спасительных двушек. Это была гарантия сохранения связи с внешним миром, ограниченном, правда, пределами родного города или поселка. О том, чтобы вот так запросто пообщаться с иногородним другом или, что вообще казалось невероятным, с заграницей, никто и помыслить не мог. Для этих целей существовали специальные переговорные пункты, где после томительного ожидания слышался наконец голос в трубке. Треск и посторонние шумы на линии не в счет! Хуже, если вызываемый абонент просто отсутствовал в месте нахождения своего телефонного аппарата. Тогда вся процедура повторялась на следующий день.

Для каждодневных нужд тут и там были разбросаны серые металлические будки телефонов-автоматов. Если и существовал какой-то план размещения их в городской среде, то нам он неведом. Иногда будки стояли в начале и в конце длинного жилого дома, но нередко приходилось пробежать несколько кварталов в поисках одной из них. Коренные москвичи знали места скопления переговорных устройств. Особенно кучно они группировались в центре города, ведь там находились все культурно-развлекательные заведения, большинство кафе и ресторанов, там же назначали свидания. Часто отсутствие заветной монетки могло в корне изменить отношения, разрушить успешно начатое дело или даже помешать предотвращению ЧП домашнего масштаба, будь то невыключенный утюг или незакрытый кран. Поэтому на просящего никогда не смотрели косо и совершенно безвозмездно делились медью.

У рачительных и запасливых хозяев в прихожей всегда стояла емкость с мелочью. Ее позвякивание в кармане внушало спокойствие и уверенность. На улице можно было не только позвонить, а потому никого не удивлял такой, например, вопрос: «По трешечке не разменяете?» или «Простите, у вас трех копеек не найдется?». Опять же это отнюдь не означало, что некто, руководствуясь народной мудростью «с миру по нитке», собирается таким способом накопить на «Запорожец» или «Москвич». Вполне платежеспособный гражданин просто-напросто хотел пить, а стакан вожделенной сладкой газировки в ближайшем автомате стоил ровно три копейки. Шипучку без сиропа можно было получить всего за одну. Конечно, разовых стаканчиков у автопоилки не было и в помине. Имелся один граненый «мухинский» стакан, который тут же в специальном фонтанчике ополаскивался и вновь наполнялся. Временные трудности возникали, когда емкость заимствовали местные любители более крепких напитков. В их среде, правда, считалось хорошим тоном вернуть стакан 
на место после использования. Попадались иногда и несознательные граждане, изобретательностью и силой не обиженные. Кое-кто из них умудрялся так двинуть несчастному механизму под ложечку, что тот, охнув и шумно выдохнув, извергал из своего нутра шипящую струю. Заметьте, совершенно бесплатно. Отдельные личности подобным варварским способом вышибали мелочь в телефонных будках, но это было труднее и не всегда удавалось. В наши дни флер советскости присутствует в интерьере многих точек питания. Там можно встретить и уличные автоматы с газировкой. Реплики, конечно. Только разливают они теперь совсем другие напитки по другим ценам.

К схожей теме имеют отношение и другие, странно звучащие для уха нашего современника, вопросы. В их числе: «Повторять будете? За вами стоять можно?» и совсем уж прямолинейный «Кружечка освободится?». На последний вопрос обычно следовал ответ «Не скоро», чтобы вопрошающий не стоял над душой и не мешал процессу. Процессу неспешного употребления пенного напитка под названием «Пиво Жигулевское» или просто «Жигули». Нетрудно догадаться, где можно было наблюдать подобную мизансцену. Это пивной бар, но не тот, каким знаем мы его сегодня, с улыбчивыми официантами, предлагающими на выбор несколько сортов пива и изрядное количество аппетитных закусок. Нет, это советское заведение называлось «пивной автомат», или в просторечье «автопоилка».

Подобные точки притяжения присутствовали во всех крупных городах, но было их не слишком много, поэтому давка там была страшная. В независимости от времени суток и дня недели. В столице в каждом районе была своя излюбленная пивнушка, но всенародная любовь досталась лишь некоторым - таким, как «Ракушка», «Жигули» или знаменитая «Яма» в Столешни- ковом переулке. Существовали, конечно, и сидячие пивные, с удобными столиками и официантами, гордыми от сознания собственной значимости, но это были заведения иного рода. «Стоячки» были демократичны и всем доступны. Всего двадцать копеек, опущенные в щель автомата, гарантировали получение почти полной поллитровой кружки. Как раз тут странные вопросы обретали смысл! Все дело было в кружках, которых катастрофически не хватало. Ничего не поделаешь, приходилось занимать очередь. Кто же мог подумать, что через много лет продукция советской стекольной промышленности начнет пользоваться повышенным спросом. Из антикварных магазинов и с блошиных рынков емкости попадают в коллекции или украшают собой пивные посиделки. Наиболее ценны те экземпляры, на донышке которых отчетливо видны цена и пятиугольный знак качества.

Как принято, к кружке пива полагалась соответствующая закуска. Из небогатого выбора лучше всего шли соленые сушки, по копейке штука - наш ответ германскому брецелю. Кое-где встречались и порционные отварные креветки, такие мелкие, что возникал вопрос относительно их видовой принадлежности. Были и бутерброды с колбасой «собачья радость» или увядшим «загнутым» сыром. Ассортимент всех устраивал, и публика собиралась самая разношерстная. От простых работяг до служащих близлежащих учреждений; от прогуливающих лекции оболтусов-студиозов до «товарищей ученых, доцентов с кандидатами». Все плечом к плечу стояли вкруг высоких столов и горячо спорили о насущных проблемах современности. Вовсю травили анекдоты «про руководителей партии-правительства», порой весьма смелые. Автоматы были и дискуссионным клубом, и биржей. Библиофилы, фарцовщики, художники, коллекционеры всех мастей встречались там, об- 
суждали дела, заключали незаконные по тем временам сделки. Немалому числу будущих успешных предпринимателей и творческих работников довелось постоять с протянутой рукой в ожидании порожней стеклотары. Стекло ценилось во всех своих воплощениях. Ни одна пронесенная под полой и опорожненная бутылка не пропадала зря. Вопрос «Бутылочка нужна?» всегда предполагал отрицательный ответ, и «хрусталь» перекочевывал в объемистые торбы вездесущих сборщиков. Им прямой профит и обществу польза. А ныне? Где тот «Пункт приема стеклотары. Часы работы 8.00-20.00»?

Следует помнить, что во времена господства соцреализма число ярых сторонников ЗОЖ было весьма незначительным. Да, спорт любили все, но это никак не сказывалось на уменьшении числа курильщиков. Сегодня, обращенный к случайному прохожему вопрос «Простите, у вас закурить не найдется?» или неформальное «Извини, брат, сигареткой не богат?» покажется, по меньшей мере, странным, а то и вовсе неприличным. Активная и обоснованная антитабачная пропаганда превратила любителей подымить чуть ли ни в социальных изгоев, меры по их изоляции от некурящей части общества кое-где чрезмерно радикальны. Сигареты, как и везде в мире, стоят дорого, и это еще не предел. Казалось бы, еще вчера вытянуть из пачки ценой от 14 до 40 копеек сигарету и запросто поделиться с собратом-курильщиком было обычным делом. В наши дни это уместно только в кругу хорошо знакомых людей, причем просьба сопровождается обычно извинениями за собственную слабость и рассуждениями о том, что пора уже кончать с пагубным пристрастием. Образ человека с сигаретой в зубах претерпел трансформацию: из героя, рубахи-парня, которому все нипочем, он превратился в опасного для окружающих лузера с дурным вкусом и плохими манерами.
Поинтересоваться «Который час?» было делом обычным. На улице то и дело слышалось: «Дядь, а сколько времени?» или немного виноватое: «Простите, не подскажите, который час? Часы ито-то остановилисъ. И бесконечное число вариаций на эту тему. У советского школьника первые наручные часы появлялись классу к шестому-седьмому и были для него предметом гордости и символом причастности взрослому миру. Небрежно вскинутая рука, и взорам одноклассников открывалось запястье, украшенное «Победой», «Востоком» или «Славой». Что же говорить о тех, кому посчастливилось стать обладателем японского или даже швейцарского механизма. «Сейко», «Ситизен», «Омакс», «Булова» - названия заморских брендов звучали, как музыка. Обладали ими счастливчики, побывавшие «в загранке», или же те, кто выложил сумму, равную одной, а то и двум, месячным зарплатам инженера. Не в магазине конечно, а на черном рынке. «Патек Филипов» и прочих «Вашерон Константэнов» никто тогда и в глаза не видел, зато сегодня обеспеченные соотечественники их коллекционируют. Впрочем, с точки зрения утилитарности нет никакой разницы между механическим «Ролексом»с автозаводом стоимостью в 15-20 тысяч долларов и часами за сотню-полторы, в которых раз в пару лет надо заменить батарейку. И те, и другие точно показывают время, а именно для этого они и были созданы. Часы в своем классическом виде давно уже утратили позиции предмета незаменимого в каждодневном обиходе. Время само напоминает о себе везде, где возможно: в метро, в салоне автомобиля, на дисплеях всевозможных гаджетов. Так зачем же о нем спрашивать?

Все меньше интересуются горожане и тем, как добраться из пункта А в пункт Б. Вопрос «Как пройти в библиотеку?» услышишь, разве что просматривая в который раз «Операцию ЫІ», или задашь сам, если подвела 
батарея смартфона. Навигатор уверенно приведет вас в любую библиотеку, как бы далеко она ни находилась. С интернетом и без него, с подсказками на русском или любом другом языке на выбор. Доходит до абсурда: некоторые включают навигацию, перемещаясь по маршруту, не единожды хоженому-перехоженному. Просто так, по инерции. Обратная сторона цифровизации это потеря навыков ориентирования и отчасти свободы выбора. Недалек тот день, когда вместо привычного «Простите, как пройти...» мы услышим что-то типа «Простите, ... тарл не раздадите?».

Впрочем, на такой случай всегда есть такси. А если еще и времени в обрез, то прямая дорога на обочину. И там стоять, призывно размахивая рукой, пока не остановится авто с шашечками или убитая «копейка» «с лихим водилой» за рулем. Последующий диалог мог звучать примерно так: «Шеф, свободен?» - «Нет, на вызов еду» - «Два счетчика плачу!» - «Садисъ, поехали». Или вот так, это уже в постсоветское время: «До иентра сколько будет?» - «Двести рублей, дорогой» - «Да я только вчера за сто ездил!» - «Пробки везде сегодня! Ладно, поехали, сто пятьдесят дашъ, нормально будет. Бъстро довезу». И на полную громкость «Радио шансон». Но забываются постепенно эмоциональные переговоры. Слова больше не нужны. Кликаешь иконку на экране, вводишь исходные данные и вот уже через несколько минут едешь по заданному маршрут. Стоимость известна заранее, а музыку можно выключить или включить по собственному желанию. Недалек тот день, когда водителя в транспортном средстве не будет вовсе. К чему лишние разговоры?

В дымке времени исчезают и такие когда-то привычные вопросы: «А ито дают? Скажите, ито я за вами» или «Здесь на румынскую стенку пишут? Меня тоже запишите». Получив строгое предупреждение, что пере- кличка по первым вторникам каждого месяца, обнадеженный соискатель стенки удаляется. Если повезет, то через пару лет он станет счастливым обладателем гарнитура стоимостыю в три-четыре его годовые зарплаты.

А этот разговор напоминает диалог из советского фильма о буднях секретных агентов. С осторожностью, озираясь по сторонам, некто входит в магазин. Подозвав продавца, он тихо сообщает пароль: «Я от Семена Ивановича». Тот тем же заговорщицким шепотом отвечает: «Подойдите к служебному входу со двора. Вам финнов или югославов?» Что-то ответив, мужчина выходит и через минуту оказывается в условленном месте. Там через приоткрытую дверь ему вручается большая коробка, а в ответ он передает конверт. Засунув добычу в рюкзак, спешит к автобусной остановке. Все, свершилось. Долгожданные финские сапоги на «манке» (утолщенная обливная подошва), наконец, куплены, и теперь весь родной НИИ будет долго тихо умирать от зависти. Заметим, что подобные действия сурово преследовались, а нарушителей ожидало наказание в виде крупного штрафа или в некоторых случаях даже лишения свободы. Колоритные же диалоги как примета времени свободно продолжают жить в фильмах, книгах и многочисленных анекдотах о советской торговле и обустройстве быта гражданами большой страны.

Сохраняя особое место в системе сегодняшних словесных коммуникаций, эти и другие, чуть забытые, для кого-то непривычно звучащие реплики являются частью языковой культуры нашего народа. Они помогают окунуться в атмосферу недавнего прошлого, почувствовать дух ушедших десятилетий. Они же и мостик к предметам культуры материальной, стремительно меняющейся, приобретающей все новые формы. Возможно, как и эпистолярный жанр, которому многие годы пророчили забвение и который на наших глазах 
возрождается в пику цифровизации, диалоги городского коммуникационного пространства советского времени обретут новое звучание и новый смысл.

\section{Vladimir Nazarov}

economist, marketer, Member of the Council of the Guild of marketers

of the Russian Federation, Member of the Union of journalists of Russia (Moscow)

vlad284@mail.ru

\section{Words, you won't say}

Everyday life of the Soviet past brought into the world cultural codes and behavioral stereotypes, which today evoke not only nostalgic memories of people born in the USSR, but also the time-honored interest of new generations, who are are attracted by the anthropology of Sovietism.

Keywords: anthropology of Sovietism, socio-cultural space of the city, communicative behavior, communicative environment, cultural code, reconstruction

\section{Елена Теплова}

\section{Визуальные образы советского детства}

Продолжая серию статей по антропологии образования, автор рассматривается вопрос об использовании визуальных образов детей как способа формирования представления о «счастливом советском детстве» с целью воспитания достойного гражданина советской страны.

Ключевые слова: советское детство, визуальные образы, дети, подростки, молодежь, кино, живопись, идеология, позитивная визуальная символика, плакат, счастье, мифологема «счастливое советское детство», образ ребенка

Во второй половине прошлого века в СССР активно создается идеологическая установка «счастливое советское детство», отражающая ценности и нормы, касающиеся детей и подростков. Воспитательные идеи и технологии, как и в любом обществе, в Советском Союзе
Теплова Елена Феликсовна, кандидат исторических наук, доцент кафедры культурологии, заместитель директора Центра историко-культурных исследований религии и межцивилизационных отношений, Институт социально-гуманитарного образования, Московский педагогический государственный университет (Москва),ef.teplova@mpgu.su были связаны с представлениями о будущем и о значимости детства как определяющего этапа формирования личности.

Общепринятые нормы предписывали, как должен выглядеть маленький или взрослеющий ребенок Страны советов, какие черты характера и занятия для него предпочтительны, а какие недопустимы; как он должен взаимодействовать со старшими и младшими; что нужно запрещать и что поощрять. Все это создавало особую воспитательную систему, отражавшуюся во всех социальных сферах - образовании, искусстве, семейных отношениях, моде, идеологии и т. д. [3].

Все сферы общественной жизни должны были укреплять и активно демонстрировать (если не удавалось полностью, по сути, соответствовать) ценностную модель советского детства, которая определялась официальной общественной идеологией. Огромная роль в этом отводилась внешним образам детей и подростков. Сохраняя идеи политики «монументальной пропаганды», провозглашенной в первые месяцы существования советской власти, визуализации, внешним формам придавалось особое значение. Ребенок, окруженный зрительными образами положительных, радостных, здоровых детей, должен был не только ощущать себя сопричастным к счастливому дет- 